\title{
Features of Social Play in 8- to 11-Year-Olds in China: Exploring Children's Own Perspectives
}

\author{
RAO Zhen | ORCID : 0000-0001-5381-8170 \\ Centre for Research on Play in Education, Development and Learning, \\ Faculty of Education, University of Cambridge, 184 Hills Road, Cambridge, \\ $\mathrm{CB} 2$ 8PQ, UK \\ zr23o@cam.ac.uk \\ Jenny GIBSON | ORCID : 0000-0002-6172-6265 \\ Centre for Research on Play in Education, Development and Learning, \\ Faculty of Education, University of Cambridge, Cambridge, UK \\ jlg53@cam.ac.uk \\ Bill NICHOLL | ORCID : 0000-0003-4089-7820 \\ Faculty of Education, University of Cambridge, Cambridge, UK \\ ban22@cam.ac.uk
}

\begin{abstract}
This paper presents a small-scale exploratory study investigating social play among 8to 11-year-old Chinese children. Semi-structured interviews were carried out with six self-selected pairs of children in six natural settings (two homes, two parks, and two playgrounds). Children's responses to the interview questions and their spontaneous play activities during the interview were audio-recorded and analysed thematically based on transcription. Pretend play and games with rules were found to be two popular types of social play among these children. Three features of social play activities were identified: combination of real-life elements and creation, combination of variation and consistency, and combination of conflicts and compromises. According to children's own perspectives, being appropriately challenged, being fair, and having autonomy were important for them during play. Children also reported positive emotions during play and negative emotions when not having opportunity to play. Limitations and implications of the study are discussed.
\end{abstract}




\section{Keywords}

social play - Chinese children - pretend play - games with rules - paired interview children's voice

\section{Introduction}

In contrast to the widely acknowledged importance of play in early childhood (e.g. Garner \& Bergen, 2015; Lillard, 2015; Rao \& Gibson, 2019), play in middle childhood has been much under-researched. In recent years, growing evidence has indicated that play continues to constitute a critical part of older children's lives, and could facilitate their cognitive, social and emotional development (e.g. Bergen \& Fromberg, 2009; Howard et al., 2017; E. D. Smith \& Lillard, 2012). This body of evidence, however, has largely come from studies with children in Western cultures, and cannot be assumed as applied to other cultures. For example, parents from China and other Asian countries have been found to value play less and place more importance on academic achievement compared to Euro-American parents (Parmar et al., 2004). These differences in parental beliefs on the value of play and emphasis on academic outcome, along with other cultural, social and economic characterises, could affect children's play in a variety of ways (e.g. play partner, play resources and time to play) (Gaskins, 2013; Roopnarine, 2011). Exploring 8- to 11-year-old Chinese children's perspectives on their social play, the current study aimed to contribute to the global literature on play in middle childhood (e.g. universalities and variations) under the influence of culture and its possible relations to child development and education.

Play has been conceptualised as activities characterised by spontaneity, autonomy ${ }^{1}$, means over ends and positive affect. During play, one has the freedom to initiate or end it, and has choices in terms of how to behave (Burghardt, 2009). Performed for its own sake, play is intrinsically rewarding and often accompanied with positive affect indicated by smiling and laughter (Pellegrini, 2009). Rather than merely observable behaviour, play has also been argued to be a psychological state. Empirical evidence has shown that children may perceive activities to be "play" or "not play" by using cues such as the location of activities, absence/presence of adults and the opportunity to make their own choices (Howard, 2002).

Whereas play can be performed solitarily or with others (e.g. parent, sibling, friend), the present study focuses on social play where a child plays with one or

1 Autonomy is referred to the feeling of volition and the experience of integration and freedom (Deci \& Ryan, 2000). 
more partners (Howes, 2011). This focus is chosen because of the important role of social play in children's cognitive, social and emotional development. As Vygotsky (1978, p. 86) suggested, social play could provide children with the opportunity to be guided by adults or collaborate with more capable peers, which creates "a zone of proximal development" that allows children to development through play. During social play, negotiating and compromising with other players could facilitate the development of communicative and social skills (Fromberg \& Bergen, 2015). By sending play partner the message "this is not serious", social play could provide children with a less risky social situation to try out combination of behaviours and help them develop flexible thinking and creativity (Bruner et al., 1976; P. K. Smith, 2010). The opportunity to try out various emotional experience and expression during social play could also facilitate the development of emotional understanding and regulation (Meyers \& Berk, 2014). The rules and reciprocity embedded in social play also affords children the opportunity to develop self-control and moral judgement such as fairness ${ }^{2}$ (Devries, 2015).

Various types of social play have been proposed, among which the two most widely investigated ones are social pretend play and games with rules. ${ }^{3}$ Performed in a nonliteral way, pretend play involves using one object to substitute another, attributing pretend properties, or creating imaginary objects (Leslie, 1988). Governed by mutually agreed regulations, games with rules involve competition between players who often aim to win (Pellegrini, 2009). Although Piaget suggests that pretend play declines "between the ages of eight and twelve" (1951, p. 146), evidence has shown that this type of play continues to middle and late childhood. For example, in a questionnaire study by Smith and Lillard (2012), undergraduate students reported to engage in pretend play until 11 years old on average, with nearly half of the respondents recalling continuing pretend play over the age of 12. According to Bergen and Fromber (2009), young adults reported to engage in elaborate, long-duration pretend play between the age of 8 and 12 either at home, school or local neighbourhoods. These young adults also recalled playing games with rules generated or adapted by children themselves.

To investigate middle-childhood play from children's perspectives, Howard et al. (2017) conducted semi-structured focus-group interview with 7 - to 11-yearolds in the UK, who reported a wide range of play activities (e.g. video games, yard games, pretence, rough and tumble). Children in this study also reported

2 Fairness is referred to equality and reciprocity (Gummerum et al., 2008).

3 Despite their different characteristics, pretend play and games with rules are not strictly mutually exclusive. For example, children could adopt pretend roles while playing games with rules and obey explicit or implicit rules during pretend play. These two types of play could also be integrated into other types of play, such as physical play (Whitebread, 2012). 
positive emotions (e.g. happiness, enjoyment, feeling in control) associated with their play, and negative emotions (e.g. bored, annoyed and moody) with not being able to play. Using survey, interview and observation, Bhuya and Zhang (2019) found that 7- to 15-year-olds in India reported to play various types of games with rules, and to play at different places (e.g. playgrounds, streets, schools). Additionally, this study suggested that children associated play with positive emotions such as "happiness" and "fun".

Despite of the growing evidence on the important role of social play, a decline in play opportunities, especially among older children, has been documented (e.g. Brock et al., 2009; Gray, 2011). In China, "heavy schoolwork" has reduced school-aged children's play opportunities and been acknowledged as "harmful to the mental and physical well-being of youngsters and children" in Outline of China's National Plan for Medium and Long-term Education Reform and Development (2010-2020) (Ministry of Education, 2010, p.15). With the aim to understand Chinese children's play in middle childhood, the present study uses semi-structured paired interview to address three research questions: Firstly, what types of social play are popular among 8 to 11-year-old Chinese children? Secondly, what are the common features of these children's social play? Thirdly, what are these children's own perspectives on their social play?

\section{$2 \quad$ Method}

\subsection{Participants}

Twelve Chinese children aged between 8 and 11 from Guangzhou, China participated in this study (Table 1). A convenience sample of six children (3 girls and

TABLE 1 Overview of participants and data collection

\begin{tabular}{|c|c|c|c|c|c|c|}
\hline Participants & Pair 1 & Pair 2 & Pair 3 & Pair 4 & Pair 5 & Pair 6 \\
\hline Gender & Female & Female & Female & Male & Male & Male \\
\hline Age in years & $8 \& 9$ & 9 & 10 & 8 & $10 \& 11$ & $10 \& 11$ \\
\hline $\begin{array}{l}\text { Years of } \\
\text { friendship }\end{array}$ & $>5$ & $>7$ & 4 & 2 & $>8$ & 4 \\
\hline $\begin{array}{l}\text { Relationship } \\
\text { to each other }\end{array}$ & Neighbours & $\begin{array}{l}\text { Neighbours \& } \\
\text { classmates }\end{array}$ & Classmates & $\begin{array}{l}\text { Classmates \& } \\
\text { neighbours }\end{array}$ & $\begin{array}{l}\text { Former } \\
\text { neighbours }\end{array}$ & Classmates \\
\hline $\begin{array}{l}\text { interview } \\
\text { settings }\end{array}$ & Playground & Home & Park & Playground & Home & Park \\
\hline
\end{tabular}


3 boys) was first recruited through letters circulated to their parents. Each of these six children was then asked to select a friend to participate in this study together. All six children chose a friend of the same gender. The 12 children lived in three different districts of the city and attended eight different public schools between Year 2 and Year 5 . Nine children were single child in their families and three had one or two younger siblings. The participants were from middle-to-high ses families and all spoke Mandarin.

Prior to recruitment, the study was reviewed and approved by the institution's ethics committee. Informed consent from parents and informed assent from the children were obtained before data collection. To protect children's confidentiality, pseudonym names were used when reporting the results.

\subsection{Semi-Structured Paired Interview}

A semi-structured interview was conducted with each pair of children. As play is closely related to one's attitudes and feelings, listening to children's own voice could provide valuable information on their play which other methods (e.g. observation) may not be able to access. Rather than being interviewed individually, children in the current study were interviewed in friendship pairs. This not only allowed for examination of social interactions and social play, but also provided the opportunity for children to receive and give support to each another during interview, which could reduce the power imbalance between children and the adult researcher and encourage children to disclose real feelings (Highet, 2003).

Each pair was interviewed between 40 minutes and one hour, which was audio-recorded. All interviews began with the same questions "please can you tell me how and when you got to know each other", and "what do you usually play when you are together". Following the children's answers, more questions were raised accordingly to encourage them to explain in more detail their activities and opinions. Questions such as "who decide the rules of the game", and "how much play time do you have on weekdays and weekends" were asked to all pairs but not always in the same sequence (Appendix). Rather, they were raised according to the dynamics with the aim to facilitate the flow of the conversation and allow the children to expand or clarify their answers. Children's spontaneous play occurring during the interview was not interrupted and instead recorded as an integrated part of the interview.

\subsection{Contexts}

The interviews were conducted in six naturalistic settings (Table 1). Two pairs of children were interviewed at one of the children's homes respectively, where the researcher stayed with each pair in a room while other adults were in other rooms. Another two pairs were interviewed at two different playgrounds, 
where the children' parents were around but kept considerable distances to them. Interviews with another two pairs were carried out at two parks, during which none of the children' parents were present. These locations were chosen by the children with the aim to make them comfortable and reduce the potential power imbalance between them and the researcher (Elwood \& Martin, 2000).

\subsection{Data Analysis}

The six audio-recorded interviews were transcribed verbatim along with nonverbal communication (e.g. nodding, laughing, shaking head) (Kvale, 1996). The full transcripts were printed out and manually coded. A thematic approach driven by both theories and data was used to analyse the transcripts (Braun \& Clarke, 2006). In the first step of the thematic coding, interview transcripts were read and re-read closely by the first author, who became familiar with the transcripts. Next, initial codes were generated and written down alongside corresponding words, phrases, sentences and dialogues on the transcripts. These codes were then clustered into related ideas in searching and refining themes. Lastly, the refined themes were organised together with examples to illustrate the themes.

\section{$3 \quad$ Findings}

\subsection{Popular Types of Social Play}

The thematic coding resulted in two popular type of social play among the participants: "pretend play" and "games with rules" (Table 2).

\subsection{Pretend Play}

Most interviewees explicitly engaged in pretend play during interviews, with some children inviting the researcher to play roles in their imaginary scenarios. For example, a pair of boys (aged 10 and 11) pretended to be two bosses living together in a house (with bedrooms, study, garage, garden, and basement) which they built with Lego blocks. When a pair of girls (aged 8 and 9) sat down on a slide in a playground to be interviewed, they pretended that they and the researcher were three investigators who had just landed in an alien planet:

Qi (girl, 9): We're here to investigate. Sister (referring to the researcher), you have a notebook, so your responsibility is to take notes. I have good eyesight, so I am responsible for collecting information.

Wei (girl, 8): Then I'm the captain.

Qi: You're responsible for protecting us. 
TABLE 2 Summary of Findings from Thematic Analysis.

\begin{tabular}{|c|c|c|}
\hline $\begin{array}{l}\text { Research } \\
\text { questions }\end{array}$ & $\begin{array}{l}\text { Themes resulted } \\
\text { from thematic } \\
\text { analysis }\end{array}$ & Examples of themes \\
\hline
\end{tabular}

Popular types Pretend play

of social play

Features of social play

Children's perspectives \& creation conflicts \&
Two girls spontaneously developed an imaginary story, with one girl acting as a pet keeper while the other taking the roles of different animals

$\begin{array}{ll}\text { Games with rules } & \text { A chasing game called "cat and mice" was demonstrated } \\ & \text { respectively by two pairs of children who attended } \\ & \text { different schools }\end{array}$

Combination of

A "battle" game stimulated real battle by using fake real-life elements weapons (e.g. paper wads) created by the children; A girl used her arms to represent pets during pretend play

Combination of Two girls pretended to be the same roles with different variation \& "episodes" of plots;

consistency The "cat and mice" game and "ghost" game were played for years with rules changed from time to time

Combination of Two girls fight with each other when one was teasing the other, and made it up afterwards;

compromises Two boys got angry with each other because they had different opinions on pretend scenarios, and continued play "after a few minutes"

$\begin{array}{ll}\begin{array}{l}\text { Being appropriately } \\ \text { challenged }\end{array} & \begin{array}{l}\text { Children indicated that it was not challenged enough } \\ \text { when playing with younger children or with adults who } \\ \text { went easy on them, while it was too challenged to play } \\ \text { with much older children }\end{array} \\ \text { Being fair } & \begin{array}{l}\text { Children played Shitou-Jiandao-Bu or Caiquan to decide } \\ \text { roles on games or what to play }\end{array} \\ \text { Having autonomy } & \begin{array}{l}\text { Most children preferred the absence of adults when } \\ \text { playing with peers; Children also kept secrets about their } \\ \text { play }\end{array}\end{array}$

Children indicated feeling relaxed when playing with

Positive and negative emotions friends, and feeling "bored" and "unhappy" when they could not play with friends 
Half of the participants indicated pretend play as one of their favourite play activities which they often engaged in with close friends when they had the opportunity. "We always play this for the whole afternoon", a 10-year-old boy talked about playing with Lego mini figures. A 9-year-old girl said that she and her best friend could play the pretend pet shop "throughout the whole day".

\subsection{Games with Rules}

A second popular type of social play emerged from the thematic analysis was games with explicit rules. All interviewees mentioned playing certain forms of rule-governed games (e.g. chasing games, card games, and chess). For example, a chasing game called "cat and mice" was demonstrated respectively by a pair of 8-year-old boys and a pair of 10-year-old girls who attended two different schools. Although none of them knew how the game was introduced to their school, the basic rules of their game were almost identical. According to the rules, a child taking the role as a cat tries to catch other children who took the roles as mice. The "cat" and the "mice" have one respective base (e.g. a tree, a pillar, or any other objects agreed by all players). A "mouse" is caught if any part of their body is touched by the "cat", unless any part of their body is attached to the "mice" base. The "mice" would become hungry and need to go out of their base to "steal some oil" (imagined to be stored in the base of the "cat"). If a "mouse" uses any part of their body to touch the base of "cat", they successfully "steal the oil" and recharge their energy.

According to the interviewees, these chasing games were usually played during recess at school by a group of children. Several interviewees emphasised that these chasing games were more fun when "lots of people played together". "At first we had 5 people playing this game, then more people joined in and we have more than 10 now", an 11-year-old boy recalled about a "ghost" game which he had played in school for two years. Another girl described that she often played "cat and mice" with "a crowd of people" for 15 minutes during recess.

Features of Social Play

The thematic analysis resulted in three features of social play: combination of real-life elements and creation, combination of variation and consistency, and combination of conflicts and compromises.

\subsection{Combination of Real-Life Elements and Creation}

The first feature of the children's social play was the combination of real-life elements and creation. On the one hand, all pretend play and games with rules 
taking place during the interviews contained elements that could be found in real life (e.g. pretend roles such as mayor, police, thief and pet keeper; pretend events such as going on holiday, moving house and ordering take-away food). Apart from daily life situation, what children had learnt from school and from their own reading were also reflected in their pretend play. For example, an 11-year-old boy who enjoyed reading atlas and geographical books explained that he drew maps for two imaginary countries of which he and his friend pretended to be presidents. Among games with rules, elements from real life situation (e.g. hacking, blooding, infection and death) were also found.

On the other hand, these play activities were not simple repetitions of what had happened in real life. Rather, children added a wide range of creative elements into their pretending scenarios or games with rules. For example, a 9-year-old girl used both of her arms to represent two pets that she pretended to have. When her friend asked one of the pets who "loves saving secret money in its tummy" to "spit out some coins", the girl quickly shook one of her arms up and down while making sounds mimicking coins dropping down. "We don't need props", the girl explained, "just imagine what you are doing, and you can do it with your hands". Elements of creation in games with rules could be exemplified in a game called "boys-girls-battle". Described by a 10-year-old boy as a popular game at his school, this game stimulated real battle conditions by using fake weapons created by the pupils: boys and girls joined two opposing regiments ("boy regiment" and "girl regiment") and playfully attacked each other by throwing paper wads and shooting catapults.

\subsection{Combination of Variation and Consistency}

A second feature of the children's social play was a combination of variation and consistency. For instance, some children kept changing their imaginary scenarios while maintaining the same roles or contexts. A 9-year-old girl said that she had played the same pretend "pet shop" with her best friend at home for the past three years:

We don't feel bored. Each time the play is different. The people remain the same, but the plots keep changing...We divide them into episodes. Each day it's one episode. One episode could be long. (girl, 9)

Similarly, rules of games were also changed "slightly" or "slowly" from time to time. When unexpected problems occurred during the play, new rules were made to solve these problems. For instance, the rules of the "cat and mice" game were amended according to the children. Under the old rules, a "mouse" 
was safe from being caught only when any part of its body was attached to the "mice" base. After a new rule of joint hand was created, however, two or more "mice" could hold one hand with another with only one "mouse" attached to their base. All "mice" in such a joint-hand state were safe from being caught by the "cat", which made the game "more complex and more fun".

\subsection{Combination of Conflicts and Compromises}

A third feature of the children's social play was the combination of conflicts and compromises. All six pairs of interviewees said there were times that they disagreed with each other, with comments such as "of course all friends get mad with each other sometimes", and "how can friends never fight with each other?" According to the features of their triggers, these conflicts could be categorized into two kinds. The first category was evolving from teasing where a behaviour was thought of as play by one while being taken as an offence by the other. For example, a pair of girls said that they had a "tradition" to fight with each other once a year:

Fei (girl, 9): Once we had a fight in the subway train...She beat my butt and I beat hers back, and then we started fighting.

Lin (girl, 9): Yes, we pulled each other's hair.

Interviewer: Why did you beat her butt in the first place?

Lin: I was playing with her.

Fei: I thought she was provoking me.

The second category of conflicts was caused by disagreement of opinions. An 11-year-old boy said he and his best friend once got angry with each other because they had different ideas on how their pretend scenarios should develop. A 9-year-old girl recalled a time when her best friend wanted her to get out of a plastic house to play together, "but I didn't want to get out, and she scratched me."

Nearly all interviewees emphasized that their conflicts with friends only lasted for a short time. A 10-year-old boy said he and his friend stopped playing together and read books on their own after they disagreed with each other on how to play, "after several minutes, we chatted again and started playing together". A 10-year-old girl said she and her friend "never got angry with each other longer than a class", "we felt bored and then made it up".

Apart from the explicit conflicts recalled by the children, implicit conflicts were also reflected among the children's conversations during interview. Although the children laughed and smiled frequently while playing together, they did say "no" to each other in some occasions. However, by negotiating and 
compromising, children succeeded to resolve these implicit conflicts, keeping playing while avoiding getting angry with each other.

Analysis on children's own perspectives on their social play resulted in five themes. Being appropriately challenged, being fair, having autonomy were emphasized by children as important during play. Children also associated positive emotions with their play, and negative emotions with not having enough opportunity to play.

\subsection{Being Appropriately Challenged}

According to children's perspectives, being appropriately challenged is important to them during play. Nearly all interviewees indicated a strong preference for playing with peers of similar age or slightly older children, and expressed their dislike to play with younger children:

It's not fun playing with younger children. They are not sophisticated enough...They don't comprehend our rules. (boy, 8)

In line with their dislike of less challenging play activities was the children's autonomous choice of more "advanced" forms of play. For example, a pair of boys who enjoyed using Lego mini figures to pretend various roles insisted that their pretend play was more "advanced" than Guo-jia-jia (a Chinese word for play that involves mostly pretending family life) which in their opinion was played only by younger children.

While most interviewees preferred playing with children of similar age, one 9-year-old girl said that she also liked to play with slightly older children because "they are more capable to play with me". However, the worries of being bullied and not being able to understand older children' activities also posed challenges which some children found too difficult to handle.

We can't understand the play of those secondary school pupils even when we see them playing. They also use many internet languages which we can understand few. (boy, 11)

The difference in competence could also explain why girls and boys sometimes did not play together. As an 11-year-old boy recalled, when the "ghost" game 
was first created, some girls did join boys and played together. However, the girls "ran too slowly and always be 'infected", which means that playing with boys in this game was too challenging for the girls. Therefore, only boys who could physically compete with one another remained in the game.

Similarly, the lack of challenge during play with adults due to their incompetence or their unwillingness to play seriously were also explained by some pupils as a reason that they preferred to play with peers instead of parents.

\subsection{Being Fair}

Children's perspectives also indicated that being fair is important to them during play. In the beginning of a game when they needed to choose a "cat", or a "ghost", the children always played a form of hand games. Shitou-Jiandao-Bu (Chinese word for the game referred to as rock-paper-scissors in western countries) was the one most frequently mentioned by the children. Another similar one was Caiquan (a Chinese finger-guessing game), during which two players put out none or some of their fingers at the same time and guessed the sum of the fingers put out. When asked why they used these hand games, the children answered: "because it's fair."

\subsection{Having Autonomy}

All participants expressed their preference for playing according to their own will. Although some enjoyed playing certain type of games with their parents, most children preferred the absence of adults when playing with peers. When asked if they would think of their playful activities with friends as "play" if there were adults present, more than half of the pupils answered "no".

I feel that it's no play anymore, because they would restrain us. (girl, 10) It's not (play)...We would drive them (the adults) away...Because we would feel anxious when they are around. (boy, 10)

An interesting phenomenon associated with their preference for autonomy was the prevalence of secrets that children created and held during play. Whether it was a "war" with other children, a funny imaginary role based on a real friend, some coconut shells deliberately buried in the sand, or a "secret base" of a pretend planet, these secrets were kept enthusiastically as a way to play autonomously and avoid the interference by others. According to a 10-year-old boy, he often told his best friend funny stories about his play at school, which he did not tell his parents who may interfere with their play choices. 


\subsection{Positive and Negative Emotions}

Children's perspectives indicated that they associated positive emotions with play, and negative emotions with not having enough play opportunities. Feeling relaxed was mentioned by most participants as one of the reasons they liked to play. "Many people feel that their study is too stressful and want to cry", a 10-year-old girl commented that play made them feel relaxed in a not boring way, "you're relatively free when you play, while lying on bed is just lying and it would be boring...you can change ways to play". Another two girls explained why play was relaxing:

Qi (girl, 9): Play is a kind of rest. If you continue doing something without rest, you will do it worse and worse.

Interviewer: Is there any difference between play and other kind of rest such as sleep?

Qi: You won't be happy when you sleep. You laugh when you play.

Associated with their fondness of relaxation was a striking similarity among the children's busy daily schedule and limited social play opportunities. At least half of the children said they had "little" time for play after school on weekdays. According to all participants, recess (ranging from 10 to 30 minutes) was the main opportunity when they could play at school, with some also referring to physical education class as a special play time. A pair of 10-year-old girls explained that they had "heavy study task" and did not have many opportunities to play at school, "so now even jumping rope in the PE class seems so much fun".

Contrast to "relaxed" and "happy", "bored" and "unhappy" were most frequently mentioned by the pupils when they could not play with friends. "If you don't play, there is no single fun in life", an 8-year-old boy said, while a 9-yearold commenting that "I feel very unhappy if I can't play. It feels like there's something always making me very angry".

\section{Discussion}

The present study provides new qualitative evidence on social play among 8to 11-year-old Chinese children. Consistent with findings in Western cultures (Bergen \& Fromberg, 2009; Howard et al., 2017) , games with rules were found to be one of the popular type of play among the participants in the current study. As opposed to Piaget (1951)'s claim that pretend play declines between the age of 8 and 12, the current study supports the continuous popularity of 
pretend play in middle childhood (Pellegrini, 2009). Interestingly, participants in the current study did emphasize that their pretend play was more "advanced" and "sophisticated" than those engaged by younger children. This corresponds to the increased elaboration of pretend play with age observed in previous studies (Bergen \& Fromberg, 2009).

The current study found three features of social play, which adds support to the theorised benefits of social play in children's cognitive, social and emotional development. The first feature - combination of real life elements and creation- is consistent with the view that pretend play "bridges the gaps between real events in the changing world and imagination within one's head" (Preissler, 2006). Whereas real life elements were frequently used in their play, children also created objects, roles and properties that do not exist in real life situation during play. This supports the argument that play facilitates the assimilation and accommodation of knowledge and the development of creativity (Bruner et al., 1976; P. K. Smith, 2010). Children's social play in the current study is also featured by a combination of variation and consistency, which could be beneficial for enhancing novelty, flexibility, and adaptability among children (P. K. Smith, 2010). A combination of variation and consistency in play may also be critical for children's emotional development. The same imaginary character or context could provide children with a sense of control and feeling of safety, whereas the amendment of imaginary scenarios allows children to try out different emotional experiences and responses, which could develop emotional understanding and regulation (Meyers \& Berk, 2014). Furthermore, children's social play in the current study is featured by a combination of conflicts and compromises. This highlights the importance of social play in developing children's communication and social skills, as well as the ability to understand others (Howes, 2011).

A distinctive dimension of the current study is the exploration of children's own perspectives on their social play. By asking children their own opinions on how they like to play, this study reveals what children think are important as players. Consistent with Vygotsky's (1978) "zone of proximal development", being appropriated challenged was indicated by children in the current study as important during play. The prevalent dislike of playing with younger children who are "too naive" and the dominate preference for playing with children of similar age or those slightly older highlights a potential function of play: to learn from more capable playmates and grow from one's actual developmental level to the level of potential development. Children also indicated a strong preference for fairness, which supports the argument that play could help children's moral and self-control development (Devries, 2015). 
Findings from the current study lend further support to the significance of control and autonomy felt by the player during play. Children prevalently preferred to play without adult being present, which is consistent with previous findings that children use adult presence as a cue to differentiate play and non-play activities (McInnes et al., 2013; McInnes et al,, 2011). The excitement that children showed when they mentioned their "secret role" or "secret base" in their play further highlights the potential of play in promoting positive emotions by providing children with a sense of autonomy (Erikson, 1995).

The opportunity to play is clearly valued by all the participants in the current study. As opposed to fun and relaxation that the participants associated with play, boredom, stress and anxiety were reported by the children when they did not have time to play. This lends further support to the theoretical arguments and previous findings on the role of play in promoting positive emotions and reducing negative emotions (Power, 2000). It also highlights the need for further investigating the relation between play and children's emotional well-being.

\section{7 Conclusion}

The current study suggests that pretend play and games with rules are two popular types of social play in 8- to 11-year-old Chinese children. These children's social play is featured by a combination of real-life elements and creation, a combination of consistency and variation, and a combination of conflict and compromise. These features support the critical role that play has in children's cognitive, social and emotional development. Children's perspectives on their own play indicate a close relation between social play and children's emotional well-being.

A distinctive feature of this study is to interview children in self-selected friendship pairs during which spontaneous play is an integrated part. Commonly the participants seemed to forget about the interview temporarily and became absorbed in their play activities. This was well reflected in the transcripts which included a large amount of dialogues occurring during play between the friends. Although this might be criticized as a sign of distraction, the spontaneous play activities and the voluntary dialogues between children are arguably important data on children's behaviours and opinions. The interspersed play activities throughout the interview also indicated that the participants were relaxed and acted naturally, which could enhance the validity and reliability of the study. Nevertheless, it is possible that children's 
accounts are limited by factors such as language ability and social desirability, future studies could use data triangulation to check the quality of children's accounts.

Due to its small sample size, the current study is limited in its generalizability. Additionally, the potential influence of the researcher (e.g. personality, status, values and bias) on the participants' behaviour and the interpretation of the data may not be eliminated (Cohen et al., 2011). Future studies including a larger and more diverse sample are warranted to better understand Chinese children's social play in middle childhood. Furthermore, observation of behaviours (both in the short and long term) and reports from other sources such as parents, teachers and peers could provide a more holistic and longitudinal picture of social play.

\section{Acknowledgements}

Zhen Rao is funded by the Economic and Social Research Council (UK) (Grant Reference: ES/Too5815/1). Jenny Gibson is funded by The LEGO Foundation. This study was funded by Cambridge Commonwealth, European \& International Trust and UK Foreign and Commonwealth Office.

\section{References}

Bergen, D., \& Fromberg, D.P. (2009). Play and Social Interaction in Middle Childhood Bergen. The Phi Delta Kappan, 9o(6), 426-430.

Bhuyan, M.R., \& Zhang, Y. (2019). A Mixed Methods Research Strategy to Study Children's Play and Urban Physical Environments in Dhaka. Journal of Mixed Methods Research, 1558689819871820. https://doi.org/10.1177/1558689819871820.

Braun, V., \& Clarke, V. (2006). Using Thematic Analysis in Psychology. Qualitative Research in Psychology, 3(2), 77-101. https://doi.org/10.1191/1478088706qpo 630 .

Brock, A., Dodds, S., Jarvis, P., \& Olusoga, Y. (2009). Perspectives on Play: Learning for life. Longman.

Bruner, J.S., Jolly, A., \& Sylva, K. (1976). Play: Its Role in Development and Evolution. Penguin.

Burghardt, G.M. (2009). Defining and Recognizing Play. In Pellegrini, A.D., \& Nathan, P.E. (Eds.) The Oxford Handbook of the Development of Play (pp. 9-18). https:// www-oxfordhandbooks-com.ezp.lib.cam.ac.uk/view/10.1093/oxfordhb/ 9780195393002.001.0001/oxfordhb-9780195393002-e-002. 
Deci, E.L., \& Ryan, R.M. (2000). The 'What' and 'Why' of Goal Pursuits: Human Needs and the Self-Determination of Behavior. Psychological Inquiry, 11(4), 227-268. https://doi.org/10.1207/S15327965PLI1104_01.

Devries, R. (2015). Games with Rules. In D.P. Fromberg, D. Bergen, (Eds.) Play from Birth to Twelve: Contexts, Perspectives, and Meanings (3rd.ed) (pp. 151-157). Routledge.

Elwood, S., \& Martin, D. (2000). "Placing" Interviews: Location and Scales of Power in Qualitative Research. Professional Geographer, 52, 649-657. https://doi.org/10.1111/ 0033-0124.00253.

Fromberg, D.P., \& Bergen, D., editor of compilation (Eds.). (2015). Play from Birth to Twelve [electronic resource]: Contexts, perspectives, and meanings (Third edition.). Routledge.

Garner, B.P., \& Bergen, D. (2015). Play Development From Birth to Age Four. In D.P. Fromberg, D. Bergen, (Eds.) Play from Birth to Twelve: Contexts, Perspectives, and Meanings (3rd.ed) (pp. 11-19). Routledge.

Gaskins, S. (2013). Pretend play as Culturally Constructed Activity. In M. Taylor (Ed.), The Oxford Handbook of the Development of Imagination (pp. 224-247). Oxford University Press.

Gray, P. (2011). The Decline of Play and the Rise of Psychopathology in Children and Adolescents. American Journal of Play, 3(4), 443-463.

Gummerum, M., Hanoch, Y., \& Keller, M. (2008). When Child Development Meets Economic Game Theory: An Interdisciplinary Approach to Investigating Social Development. Human Development, 51(4), 235-261. https://doi.org/10.1159/000151494.

Howard, J. (2002). Eliciting Young Children's Perceptions of Play, Work and Learning Using the Activity Apperception Story Procedure. Early Child Development and Care, 172(5), 489-502. https://doi.org/10.1080/03004430214548.

Howard, J., Miles, G.E., Rees-Davies, L., \& Bertenshaw, E.J. (2017). Play in Middle Childhood: Everyday Play Behaviour and Associated Emotions. Children \& Society, 3r(5), 378-389. https://doi.org/10.1111/chso.12208.

Howes, C. (2011). Social Play of Children With Adults and Peers. In Pellegrini., A.D., (Ed.)(2011)The Oxford handbook of the development of play (pp. 231-244). Oxford University Press.

Kvale, S., (1996). InterViews: An introduction to qualitative research interviewing. SAGE. Leslie, A.M. (1988). Some Implications of Pretense for Mechanisms Underlying the Child's Theory of Mind. In Janet W. Astington, Paul L. Harris, David R. Olson (eds.), Developing Theories of Mind, Cambridge University Press.

Lillard, A.S. (2015). The Development of Play. In Handbook of Child Psychology and Developmental Science. http://onlinelibrary.wiley.com/doi/10.1002/9781118963418 .childpsy211/abstract.

McInnes, K., Howard, J., Crowley, K., \& Miles, G. (2013). The Nature of Adult-child Interaction in the Early Years Classroom: Implications for children's perceptions of 
play and subsequent learning behaviour. European Early Childhood Education Research Journal, 21(2), 268-282. https://doi.org/10.1080/1350293X.2013.789194.

McInnes, K., Howard, J., Miles, G., \& Crowley, K. (2011). Differences in Practitioners' Understanding of Play and how this Influences Pedagogy and Children's Perceptions of Play. Early Years, 31(2), 121-133. https://doi.org/10.1080/09575146.2011.572870.

Meyers, A.B., \& Berk, L.E. (2014). Make-believe Play and Self-regulation. In E. Brooker, M. Blaise, \& S.Edwards, (Eds.). SAGE Handbook of Play and ;earning in Early Childhood. (pp. 43-55). SAGE.

Ministry of Education. (2010). Outline of China's National Plan for Medium and Longterm Education Reform and Development (2010-2020). https://planipolis.iiep.unesco .org/sites/planipolis/files/ressources/china_national_long_term_educational_ reform_development_2010-2020_eng.pdf.

Parmar, P., Harkness, S., \& Super, C.M. (2004). Asian and Euro-American Parents' Ethnotheories of Play and Learning: Effects on preschool children's home routines and school behaviour. International Journal of Behavioral Development, 28(2), 97-104. https://doi.org/10.1080/01650250344000307.

Pellegrini, A.D. (2009). The Role of Play in Human Development. Oxford University Press.

Piaget, J. (1951). Play, Dreams, and Imitation in Childhood. W. Heinemann.

Power, T.G. (2000). Play and Exploration in Children and Animals. Lawrence Erlbaum Associates.

Preissler, M.A. (2006). Play and Autism: Facilitating Symbolic Understanding. In D.G. Singer, R.M. Golinkoff and K. Hirsh-Pasek (eds) Play=learning: How play motivates and enhances children's cognitive and social-emotional growth (pp. 231-250). Oxford University Press.

Rao, Z., \& Gibson, J. (2019). The Role of Pretend Play in Supporting Young Children's Emotional Development. In D. Whitebread, V. Grau, K. Kumpulainen, M. McClelland D. Pino-Pasternak and Nancy Perry (Eds.) The SAGE Handbook of Developmental Psychology and Early Childhood Education. Sage.

Roopnarine, J.L. (2011). Cultural Variations in Beliefs about Play, Parent-child Play, and Children's Play: Meaning for childhood development. In A. Pellegrini (Ed.), Oxford Handbook of the Development of Play (pp. 19-37). Oxford University Press.

Smith, E.D., \& Lillard, A.S. (2012). Play on: Retrospective Reports of the Persistence of Pretend Play Into Middle Childhood. Journal of Cognition and Development, 13(4), 524-549. https://doi.org/10.1080/15248372.2011.608199.

Smith, P.K. (2010). Children and Play. Wiley-Blackwell.

Vygotsky, L.S. (1978). Mind in Society: The development of higher psychological processes. Harvard University Press.

Whitebread, D. (2012). Developmental Psychology and Early Childhood Education: A guide for students and practitioners. SAGE. 


\section{Appendix: Sample Questions used in Semi-Structured Interview}

(Translated from Chinese. Sequence of questions may change according to the flow of conversation)

1. Please can you tell me how and when you got to know each other?

2. What do you usually play when you're together? Why do you like to play this?

3. Can you teach me how to play it?

4. How much play time do you have on weekdays and weekends?

5. Whom do you usually play with at school and after school?

6. Do you like to play with children of similar age, or with younger children, or older ones, or all of them? Why?

7. Do you play with Mum and Dad? Is there any difference between playing with parents and peers?

8. Do you think it's still play if adults are around when you play with friends? Why?

9. Who decides the rules of the game and how are the rules made? 